\title{
The Influence of the Use Baby Walkers \\ on Toddler Locomotor Skills in Singapore 使用嬰兒學走路扶車對下肢大肌肉軍動能力的影響
}

\author{
TAN Sing Yee, Jernice Karen P. NONIS \\ The National Institute of Education, \\ Nanyang Technological University, SINGAPORE \\ 陳勳儀嘉倫羅妮斯 \\ 新加坡南洋理工學院國立教育學院
}

\begin{abstract}
Many studies have associated the use of baby walkers with rudimentary movement delays while studies on its influence on fundamental motor skills are limited. This study investigated the fundamental locomotor skills of 14 baby walker users (BWU, M Age = 49 months) with the Test of Gross Motor Development-2 (TGMD-2, Ulrich, 2000). The results showed significant differences in running and sliding. Further, that delayed rudimentary motor skills associated with the use of baby walkers do not continue into fundamental movement phase.

\section{摘要}

許多報告顯示曾使用嬰兒學走路扶車會影響下肢大肌肉運動能力。但針對兒童成長階段的資料卻有限。本報告選用了第二代 大肌肉運動能力測試工具 (TGMD-2) 探討十四位曾使用嬰兒學走路扶車的兒童(約4歲)。研究發現曾使用嬰兒學走路扶車的兒童 在跑步和滑走有明顯的差異。但卻對他們的整體下肢大肌肉運動能力沒影響。這顯示曾使用嬰兒學走路扶車對大肌肉運動能力的 負面影響不會連續到兒童成長階段。
\end{abstract}

\section{Introduction}

Parents or caregivers use baby walkers for their infants for varied reasons including mobility, keeping their infants occupied, safe and happy or even helping in learning to walk (Menezes da Cunha, 2007; Tan, Lim, \& $\mathrm{Gu}, 2003)$. The use of baby walkers is often related to adverse rudimentary motor performance such as delays in sitting, crawling, standing and/or walking independently. Serious injuries caused by the use of baby walkers can affect physical development which may also affect motor development in later years. While research on the use of baby walkers in relation to rudimentary motor development is available, that of fundamental motor skills remains limited (Burrows \& Griffiths, 2002; Garrett, McElroy, \& Staines, 2002; Menezes da Cunha, 2007; Siegel \& Burton, 1999; Thein, Lee, Tay, 1997)

\section{Baby Walkers and Rudimentary Delay}

The literature to support the idea that the use of baby walkers promotes rudimentary motor performance remains limited. Further, the link of baby walker usage and delay in rudimentary motor milestones and the onset of walking have been inconclusive (Burrows \& Griffiths, 2002; Garrett, et al., 2002; Menezes da Cunha, 2007; Siegel \& Burton, 1999; Thein, et al., 1997). 
In Singapore, Thein et al. (1997) studied 167 baby walker users age seven to 10 months at the polyclinics and found about $11 \%(\mathrm{n}=18)$ of the baby walker users showed abnormal $(\mathrm{n}=12)$ or questionable $(\mathrm{n}=6)$ Denver Developmental Screening Test (DDST-S, Lim, Chan \& Yoong, 1994) results. Of these 18 baby walker users, 94\% ( $\mathrm{n}=17)$ showed delayed gross motor development with about $89 \%(n=16)$ spent more than one hour on the baby walker daily. The authors also reported delay in attaining rudimentary locomotor milestones with the excessive use of baby walkers.

Siegel and Burton's (1999) longitudinal study of 56 full-term baby walker users (6 to $15 \mathrm{mths}$ ) who used baby walkers on an average of 2.5 hours daily, showed slight delay in sitting, crawling and walking. Similarly, Gareth et al. (2002) reported that 54\% ( $(\mathrm{n}=102 ; 48$ boys, 54 girls) of 190 four to seventeen month old fullterm infants (83 boys, 107 girls) who used baby walkers showed delays in rolling over, crawling and standing alone. Garrett et al. (2002) concluded a strong association between the duration of baby walker use and the extent of locomotor performance delay. In contrast, Burrows and Griffiths (2002) study reported no supporting evidence to suggest that baby walkers enhance motor development.

\section{Baby Walkers and Locomotor Skills}

The importance of mastering fundamental motor skills through movement education and/or sports activities during early childhood has been emphasized by many researchers (Nonis, 2005; Wang, 2004). Given that the use of baby walkers are popular amongst parents and researchers have suggested a link between baby walkers and delay in rudimentary motor milestones, research as to whether baby walker use delays locomotor skills is warranted.

The literature, however, on the influence of baby walkers on fundamental locomotor skills is limited (Menezes da Cunha, 2007). Menezes da Cunha (2007) reviewed six articles in which researchers argued against the use of baby walkers during the early years of motor development suggesting baby walkers could affect the achievement of motor milestones. The author suggested that it was inconclusive as to whether the use of baby walkers affected the development of motor skills in children and recommended future studies in this area.

\section{Gender Differences in Fundamental Locomotor Skills}

Although research suggests that locomotor skills vary with gender (Nonis, 1996; Sigmundsson \& Rostoft, 2003), these differences are negligible during the early childhood stage (Gabbard, 2004; Thomas, 2001). For example, with the exception of the sliding skill, where the girls $(\mathrm{n}=$ 50) performed significantly better than boys ( $n=45$; $\mathrm{p}<$.05), Pollatou, Karadimou and Gerodimos (2005) reported no significant gender difference in the TGMD2 Locomotor subtest of children age 5 years. Similarly, Zachopoulou and Makri (2005), reported that no significant gender difference in the divergent movement ability of children in pre-school (34 boys, 26 girls, $\mathrm{M}$ age $=4.9$ years), first (43 boys, 32 girls, $\mathrm{M}$ age $=6.3$ years) and third grade (24 boys, 32 girls, $\mathrm{M}$ age $=7.9$ years $)$. Within the Asian context, Choi Tse (2004) also revealed no significant gender difference in the locomotor skills of 90 Hong Kong children aged six to eight years old using the TGMD-2.

\section{Theoretical Rationale and Motor Development}

There are many theoretical concepts to understand motor development. The Maturation Approach is one of the earlier influential theories whereby it explains the attainment of motor skills as a process controlled by internal (genetic) rather than external (environmental) factors (Gesell, 1928; McGraw, 1935). Any environmental influence is deemed temporary as motor skills will develop automatically from a maturational perspective.

The Dynamical Systems is based on the principles of many self-organising and complex body systems interacting with the nervous system (Kugler, Kelso \& Turvey, 1982; Thelen \& Smith, 1994). The process of motor development is constantly changing and discontinuous although development is generally continuous. A new skill emerges when the underlying neuromuscular system for that skill reach a certain point to change.

In contrast, the Life-Span Approach proposes a continuous developmental link throughout the child's life span which involves four different but continuous phases (Clark \& Whitall, 1989). These include:- reflexive movement phase (in utero - 1 year old), rudimentary movement phase (0 2 years old), fundamental movement phase $(2-7$ years old) and specialized movement phase ( $>7$ years old; 
Gabbard, 2004; Gallahue \& Ozmun, 2006). In LifeSpan Approach, rudimentary motor development of infants forms the essential building blocks for fundamental motor development of toddlers and contribute to specialized movement abilities in adulthood (Gallahue \& Ozmun, 2006). The emergence of fundamental motor skills is the sensitive learning period that establishes the foundation for more complex movement abilities in later years (Gabbard, 2000). Fundamental motor skills are crucial as they form the physical behavioral competencies for many sports. Providing foundation for fundamental motor skills is essential to maximize children's movement potential and active participation in sports (Nonis, 2005; Wang, 2004).

This study hypothesized that baby walker users of age 45 to 55 months would show delay in fundamental motor skills compared to the TGMD-2 (Ulrich, 2000) norm population of same age group in the skills of run, gallop, hop, leap, horizontal jump and slide. This study aimed to provide new insights to parents and caregivers' decisions on the use of baby walkers in relation to toddler's fundamental locomotor skills.

\section{Method}

\section{Participants}

Fourteen toddlers ( 8 boys, 6 girls, M Age $=49$ months, $\mathrm{SD}=3.71$ ) were identified as Baby Walker Users (BWU) from kindergartens using parental questionnaire. The results of the TGMD-2 locomotor subtest of both nursery boys and girls were combined. Parental consent was obtained from the parents of all BWU.

\section{The Test Instrument and Training}

The locomotor subtest of the Test of Gross Motor Development - 2 (TGMD-2, Ulrich, 2000) was used to investigate the difference between BWU and TGMD-2 norm population of the same age group. The locomotor subtest of run, gallop, hop, leap, horizontal jump and slide were assessed. The TGMD-2 catered for children within the range of 3 years to 10 years, 11 months (Ulrich, 2000).

One tester was trained to observe the locomotor skills through pre-recorded videos of 10 (6 boys, 4 girls) four year olds. With the exception of the run and horizontal jump tasks, intra-rater reliability ranged from .81 to .95 ( $\mathrm{p}<.01$, Gall, Gall \& Borg, 2005, Nonis, 1996).

\section{Procedure and Test Instructions}

The tester and the BWU were familiarized with the test venue and equipment set-up. The tester demonstrated each skill with standardized verbal instructions. All BWU were tested for each skill twice in a sequence of run, gallop, hop, leap horizontal jump and slide. BWU rested between each skill.

A score of ' 1 ' was recorded when BWU performed the task and ' 0 ' when the BWU did not meet the performance criteria of the skill. All BWU completed the six locomotor tasks in no more than 20 minutes. Appreciation stickers were given to BWU after each session.

\section{Data Reduction and Analysis}

A one sample $t$ test (two-tailed) was performed to test for statistical differences of the fundamental locomotor skills between BWU and TGMD-2 norm population of the same age group using SPSS software. Using the percentage of the four years old toddlers within the TGMD-2 norm population demonstrating mastery on locomotor subtest skills (Ulrich, 2000, p. 17, Table 3.3), test values for run, gallop, hop, leap, horizontal jump and slide were derived and used to calculate the $t$ test.

Given that the mean testing age of the BWU was 49 months, the age equivalent of 4-0 years (48 months) was used as the test value to perform the $t$ test rather than the age band of 4-3 years (51 months). Age equivalent of 48 months was converted to standard score and percentile with test values of 10 and .50 respectively (Ulrich, 2000 , p. $54 \& 60$ ). The results of the combined TGMD2 locomotor subtests of both boys and girls are reported and an alpha level of $\leq .05$ was considered significant.

\section{Results}

\section{The Locomotor Performance of Baby Walker Users (BWU)}

The overall results in this study showed significant differences between BWU and TGMD-2 norm population in the locomotor subtest skills of run $(\mathrm{p}=.01)$, slide ( $\mathrm{p}$ $=.02)$, total raw score $(\mathrm{p}=.04)$ and age equivalent $(\mathrm{p}$ $=.03$, see Table 1$)$. 
Specifically, the BWU performed significantly poorer in running $(p=.01)$ but better in sliding $(p=.02)$ than the TGMD-2 norm population. However, all BWU's did not score full marks in the hop and leap tasks (see Table 1). These results support the hypothesis that the BWU performed poorer in running but rejected for slide task compared with TGMD-2 norm population of the same age group.
Although the results supported the hypothesis for run task and rejected that for slide task, the total raw score ( $p$ $=.04)$ showed overall significant difference between BWU and TGMD-2 norm population. The total raw score is the summation of the performance criteria in the TGMD2 locomotor subtest. The positive $t$ value and mean total raw score indicated that the BWU were not performing poorer than the TGMD-2 norm population (see Tables 1 \& 2).

Table 1. Results of the Skill Mastery of TGMD-2 Locomotor Subtest for BWU ( $N=14$ ).

\begin{tabular}{lllll}
\hline & $D f$ & $t$ & $p$ (two-tailed) & $\begin{array}{l}\text { Test Value } \\
(\%)\end{array}$ \\
\hline Run & 13 & -2.86 & $.01^{*}$ & .54 \\
Gallop & 13 & .13 & .90 & .13 \\
Hop & 13 & $-{ }^{-a}$ & $-{ }^{-a}$ & .14 \\
Leap & 13 & $-{ }^{a}$ & $-{ }^{-}$ & .21 \\
Horizontal Jump & 13 & .92 & .38 & .11 \\
Slide & 13 & 2.66 & $.02^{*}$ & .29 \\
Total Raw Score & 13 & 2.29 & $.04^{*}$ & 25 \\
Age Equivalent & 13 & 2.42 & $.03^{*}$ & 48 \\
(months) & & & & \\
Std Score & 13 & 1.82 & .09 & 10 \\
Percentile & 13 & 1.21 & .25 & .50 \\
\hline
\end{tabular}

Note. * One-sample $\mathrm{t}$ test (two-tailed) level of significance at $\mathrm{p} \leq .05$

a Could not be computed as all BWUs did not attain skill mastery

Table 2. Total Raw Score Means and Standard Deviations of BWU $(N=14)$ and TGMD-2 Norm Population $(\mathrm{N}=114)$ in TGMD-2 Locomotor Subtest.

\begin{tabular}{|c|c|c|c|c|}
\hline & \multicolumn{2}{|l|}{ Boys } & \multicolumn{2}{|c|}{ Girls } \\
\hline & $\mathrm{M}$ & SD & $M$ & $S D$ \\
\hline Baby Walker Users & 28.25 & 5.63 & 32 & 10.45 \\
\hline TGMD-2 norm population ${ }^{b}$ & 27 & 9 & 29 & 9 \\
\hline
\end{tabular}

Note. $^{\text {b }} \quad$ TGMD-2, Table 6.3, p. 38 (Ulrich, 2000)

\section{Age Equivalents and Baby Walker Users (BWU)}

The results showed significant difference in age equivalent at 4-0 ( $\mathrm{p}=.03)$ between BWU and TGMD-2 norm population. Specifically, the $t$ value of age equivalent at 4-0 was a score of 2.42 which indicated that overall the BWU were not performing poorer compared to the TGMD-2 norm population of same age group (see Table 1).
Although the results showed no significant difference in the standard score and percentile between BWU and TGMD-2 norm population, interpretation of the mean percentile indicated that $59 \%(\mathrm{SD}=.28)$ of the $\mathrm{BWU}$ scored at or above the TGMD-2 norm population (see Table 3). Using the standard score descriptive ratings of the BWU $(\mathrm{N}=14)$, the percentages showed that $57 \%$ $(\mathrm{n}=8)$ was within the average range and $36 \%(\mathrm{n}=5)$ ranged between above average to very superior range (see Table 4). 


\section{Locomotor Subtest Skills and Skill Mastery}

Although the means and standard deviations for running $(\mathrm{M}=6.36, \mathrm{SD}=1.15)$ and sliding $(\mathrm{M}=6.86$, $\mathrm{SD}=2.14)$ were calculated, they did not show any skill differences between BWU and TGMD-2 norm population.
Instead to further classify the significant $t$ values, the percentage of skill mastery of the locomotor tasks was a better indicator to explain the differences in running and sliding. Briefly, attaining a full score for a skill would mean the mastery achievement of that skill. The results showed that $21 \%(n=3)$ of BWU demonstrated mastery in running (see Table 5).

Table 3. Summary of Results of BWU in TGMD-2 Locomotor Subtest $(N=14)$.

\begin{tabular}{lllll}
\hline & Percentile & Std Score & Age Equivalent & Descriptive Ratings \\
\hline Baby walker users & .59 & $10-11$ & $4-0$ & Average \\
\hline
\end{tabular}

Table 4. TGMD-2 Locomotor Descriptive Rating Results of BWU (N = 14).

\begin{tabular}{cccccccc}
\hline $\begin{array}{c}\text { Descriptive } \\
\text { Rating }\end{array}$ & $\begin{array}{c}\text { Very } \\
\text { poor }\end{array}$ & Poor & $\begin{array}{c}\text { Below } \\
\text { Average }\end{array}$ & Average & Above Average & Superior & $\begin{array}{c}\text { Very } \\
\text { Superior }\end{array}$ \\
\hline$n(\%)$ & 0 & 0 & $1(7.0)$ & $8(57.0)$ & $2(14.5)$ & $2(14.5)$ & $1(7.0)$ \\
\hline
\end{tabular}

In contrast, $54 \%$ of TGMD-2 norm population mastered this skill at the age of four years. For the slide task, $64 \%(n=9)$ of BWU were able to attain mastery compared to $29 \%$ of TGMD-2 norm population. The results showed that none of the BWU attained mastery level of a full score in hopping and leaping $(\mathrm{n}=0)$. However, the TGMD-2 norm population attained 14\% and $21 \%$ in demonstrating hopping and leaping mastery respectively (see Table 5).

Table 5. BWU $(N=14)$ and TGMD-2 norm population $(N=114)$ who Demonstrated Skills Mastery in TGMD-2 Locomotor Subtest.

\begin{tabular}{lcccccc}
\hline & Run & Gallop & Hop & Leap & $\begin{array}{r}\text { Horizontal } \\
\text { Jump }\end{array}$ & $\begin{array}{r}n(\%) \\
\text { Slide }\end{array}$ \\
\hline Baby Walker Users & $3(.21)$ & $2(.14)$ & $0(.00)$ & $0(.00)$ & $3(.21)$ & $9(.64)$ \\
TGMD-2 norm population ${ }^{c}$ & $(.54)$ & $(.13)$ & $(.14)$ & $(.21)$ & $(.11)$ & $(.29)$ \\
\hline
\end{tabular}

Note.c TGMD-2, Table 3.3, p. 17 (Ulrich, 2000)

\section{Discussion}

\section{The Fundamental Locomotor Skills of Baby Walker Users (BWU)}

The BWU age 45 to 55 months performed significantly poorer in running $(\mathrm{p}=.01)$ but better in sliding $(\mathrm{p}=.02)$ than the TGMD-2 norm population of the same age group. With the exception of run and slide, no significant difference in gallop, hop, leap and horizontal jump was found from the mastery demonstration of TGMD-2 locomotor skills. In addition, the BWU in this study did not attain mastery in hopping and leaping.

\section{The Skill of Run and Slide}

Infants who used baby walkers performed poorer in running (21\%) and were better performers for the sliding task $(64 \%)$ similar to Chinese toddlers in Hong Kong (Wong 
\& Cheung, 2006). Given that walking is a precursor to running (Gallahue \& Ozmun, 2006), it is speculated that the baby walker could have influenced early walking at infancy.

In Pallatou et al.'s study (2005) although older children, they showed similar means in running performance of BWU. However, BWU mean slide score was better than the Greek children in the same study (Pallatou et al., 2005). It is inferred that there appears to be no developmental differences in their running performance which could possibly mean that the BWU in this study may run better than the Greek children if they were of the same chronological age.

Overall, the inconsistent findings gathered from the comparison of the BWU in this study with both Pollatou et al.'s (2005) and Wong and Chueng's (2006) studies could not provide a concrete inference that the BWU in this study were exhibiting poorer running skills. However, variations in their locomotor performance due to cultural differences could be one reason. Although, a comparison within the Asian context as in the case of Wong and Cheung's study provided a better reflection of the BWU's locomotor performance against the TGMD2 norm population, the sampling population of this study was 14 as compared to the Hong Kong toddlers $(\mathrm{N}=$ 245) of same age group (Wong \& Chueng, 2006). Thus, it is recommended that a larger sample be used in future studies.

The sliding skills of BWU in this study have surpassed all the children in both studies (Pollatou, et al., 2005; Wong \& Chueng, 2006). It is suggested that the BWU in this study were more proficient sliders compared with both Greek and Hong Kong Chinese children. One possible explanation for the better sliding performance of BWU is that sliding could be an acquired skill from the use of baby walkers. BWU often need to slide and drag their feet to their targeted destinations. Given the opportunity for more sliding practices with the use of baby walkers (environment factor) during the rudimentary movement phase, this would establish the foundation for fundamental sliding skill. This is consistent with the theoretical perspective of Life-Span Approach which recognises environmental factors and states rudimentary motor development as the essential building blocks for fundamental motor development of toddlers (Gallahue \& Ozmun, 2006). In addition, Gabbard (2000) and Payne and Isaacs (1995) also believe in capturing sensitive learning period of motor skills during early childhood for later growing years. Consequently, using baby walkers during early childhood could fall within the sensitive learning period of which sliding skills at the initial stage is acquired and therefore being enhanced at the mature stage.

Alternatively, significant differences in run and slide tasks found between BWU in this study and TGMD2 norm population could be attributed to individual differences. However, individual differences do not include biological factors such as gender differences. This is because the review of the literature has suggested no significant gender difference in gross motor development (Pollatou, et al., 2005; Zachopoulou \& Makri, 2005) which includes locomotor skills during early childhood age $(2-6$ years old) and the BWU (M age = 49 months) falls within.

The Dynamical Systems Approach recognises the interaction among the task (locomotor skill), the individual (infant) and the environment (baby walker; Garcia \& Garcia, 2006). According to these authors (Gabbard 2004; Gallahue \& Ozmun, 2006), the onset of running is within the age range of 14 months to six years old. Though the use of baby walkers appeared to be an environmental factor, it did not appear to trigger a phase shift as all BWU did exhibit running ability of which is still within the onset age range of running.

Instead, the Maturation Approach which recognises individual differences is proposed to explain the phenomenon of the running and sliding performance of BWU in this study. The Maturation Approach explains the attainment of motor skills as a developmental process controlled by internal rather than external factors (Gesell, 1928; McGraw, 1935).

The poor running performance of BWU in this study could be that their running skills have not reached the same maturation level as the TGMD-2 norm population due to individual differences. Though the BWU of four year olds only attained $21 \%$ mastery in running, their running skills were still within an acceptable range given that the mastery of running task of Hong Kong Chinese children $(\mathrm{N}=1228)$ age three to 10 demonstrating TGMD-2 running mastery at mature stage ranged from lowest $1.7 \%$ to highest $96.6 \%$ (Wong \& Cheung, 2006). 
In contrast, the high mastery level of sliding reflects the matured sliding skills of the BWU in this study. However, given that the age range of onset of sliding is from three to six years old (Gabbard 2004; Gallahue \& Ozmun, 2006), the sliding skills of the BWU were still within this given age range.

The first and last performance criteria of the TGMD-2 locomotor subtest were running and sliding respectively. It is suggested that the BWU may have developed stranger anxiety which caused them to have poor running performance at the beginning but they may then overcome stranger anxiety at the last sliding action. Similar observation on stranger anxiety was seen during the tester's training session of non-participating toddlers.

Another explanation could be related to tester's reliability. It was harder to assess the BWU's actual running performance on the spot which was reflected in the tester's reliability coefficient in running $(r<.08)$ as the task of running was the first test item and running requires fast-moving actions. Based on this observation, it is recommended that a randomized sequence of the test items be made for future studies.

\section{The Skill of Hop and Leap}

All BWU in this study did not attain the mastery of hop and leap tasks according to the performance criteria of TGMD-2 locomotor subtest although their age group of 45 to 55 months falls within the age range of the onset of both skills (Gabbard 2004; Gallahue \& Ozmun, 2006). Overall, the BWU performed poorer in both hopping and leaping skills compared with the TGMD-2 norm population. This finding is consistent other studies (Choi Tse, 2004; Wong \& Cheung, 2006). For example, the percentage of Hong Kong Chinese toddlers age four demonstrating mastery on hop and leap tasks were $4.1 \%$ and $35.1 \%$ respectively with hopping classified as the most underdeveloped locomotor skill (Wong \& Cheung, 2006). However, Wong and Cheung's (2006) study reported that children at age three and five years did not attain mastery in demonstrating hopping.

Similarly, Choi Tse's (2004) study on 90 Hong Kong children (45 boys, 45 girls) of older age group from six to eight years old also revealed hopping as an underdeveloped locomotor skill with only two children attaining mastery in hopping using the TGMD-2.
Consequently based on these findings, it can be expected that irrespective of the use of baby walkers, four years old toddlers tend to perform poorly in the hop and leap tasks.

Overall, studies that used TGMD-2 reported varying levels of hopping performance (Choi Tse, 2004; Pollatou, et al., 2005; Wong \& Cheung, 2006). In examining the performance criteria of the TGMD-2, the mastery of hopping requires the child to hop three consecutive times on both right and left foot. The review of literature indicated that the task of hopping is dependent on the choice of lower limbs (Nonis \& Parker, 2005; Nonis, et al., 2006). However, the TGMD-2 neither focuses on lower limb preferences nor gives BWU the choice of lower limb to exhibit hopping. This could have affected the results of the hop task in studies which used TGMD2. It is recommended that limb preference be included when assessing hopping skills in future studies.

The movement of leaping requires the combination of running and lifting the body off the ground as well as the coordination of upper and lower limbs (Gabbard, 2004; Gallahue \& Ozmun, 2006). Drawing inference that the BWU in this study performed significantly poorer in running, this could be one reason that none of the BWU in this study attains leap mastery as leaping is dependent on the proficiency of running.

Using the theoretical perspectives proposed for the run and slide tasks, the inability to attain mastery of hop and leap tasks could be due to individual differences. The Maturation Approach which explains the attainment of motor skills as a developmental process controlled by biological factors related to neural maturation (Gesell, 1928; McGraw, 1935) is used to explain the immature hopping and leaping skills. Furthermore, the BWU may not have attained the motor maturation to exhibit mastery in hopping and leaping.

In summary this study does not support the literature that the use of baby walkers showed motor performance delays (Burrows \& Griffiths, 2002; Garrett, et al., 2002; Siegel \& Burton, 1999; Thein, et al., 1997). The BWU in this study did not exhibit poorer locomotor skills than the TGMD-2 norm population of the same age group. 
The Dynamical Systems Approach (Kugler, Kelso \& Turvey, 1982; Thelen \& Smith, 1994) and the LifeSpan Approach (Gabbard, 2004; Gallahue \& Ozmun, 2006) propose that environmental factors (baby walker) have a significant influence on future motor performance. However, both theories could not be used to explain why the BWU in this study did not show overall poorer fundamental locomotor performance compared with the TGMD-2 norm population of the same age group.

Instead, the Maturation Approach (Gesell, 1928; McGraw, 1935) appears to offer a better explanation where the use of baby walkers serves as a short-term environmental factor influencing fundamental locomotor skills. Under Maturation Approach, any environmental influence such as baby walkers is considered to be temporary. Rudimentary motor delays due to the use of baby walkers are short-term and do not influence future fundamental locomotor performance. This could explain why the BWU of age 45 to 55 months in this study were not exhibiting poorer locomotor skills than the corresponding toddlers of the similar age group in the TGMD-2 norm population.

\section{Conclusion}

In conclusion, the findings of this study suggest that with the exception of running, the use of baby walkers does not pose any significant impact on fundamental locomotor skills. However, one would suggest that the use of baby walkers could enhance the performance of sliding skills. It is recommended that future studies would include a larger sample size of similar cultural background. In addition, the overall gross motor development using both locomotor and object control subtests of the TGMD-2 is recommended.

\section{References}

Burrows, P., \& Griffiths, P. (2002). Do baby walkers delay onset of walking in young children? British Journal of Community Nursing, 7 (11), 581-586.

Choi Tse, K. (2004). A preliminary study on gross motor performance of Hong Kong children aged 6-8 years. Journal of Physical Education \& Recreation (Hong Kong), 10(2), 67-72.
Clark, J. E., \& Whitall, J. (1989). What is motor development: The lessons of history. Quest, 41, 183202.

Gabbard, C. P. (2000). Outcome-based preschool physical education. International Journal of Physical Education, 37(1), 17-23.

Gabbard, C. P. (2004). Lifelong motor development $\left(4^{\text {th }}\right.$ ed.). San Francisco: Pearson Benjamin Cummings.

Gall, J. P., Gall, M. D., \& Borg, W. R. (2005). Applying education research: A practical guide $\left(5^{\text {th }} \mathrm{ed}\right.$.). Boston: Pearson Education, Inc.

Gallahue, D. L., \& Ozmun, J. C. (2006). Understanding motor development infants, children, adolescents, adults $\left(6^{\text {th }}\right.$ ed.). NY: McGraw-Hill.

Garcia, C., \& Garcia, L. (2006) A motor development and motor-learning perspective. Journal of Physical Education, Recreation \& Dance, 77(8), 31-33.

Garrett, M., McElroy, A. M., \& Staines, A. (2002). Locomotor milestones and babywalkers: Cross sectional study. British Medical Journal, 324, 1494.

Gesell, A. (1928). Infancy and human growth. New York: Macmillan.

Kugler, P. N., Kelso, J. A. S., \& Turvey, M. T. (1982). The development of movement control and coordination. New York: John Wiley.

Lim, H. C., Chan T., \& Yoong, T. (1994) Standardisation and adaption of the Denver Development Screening Test (DDST) and Denver II for use in Singapore. Singapore Medical Journal, 351, 156-60.

McGraw, M. (1935). Growth: A study of Johnny and Jimmy. New York: Appleton-Century-Crofts.

Menezes da Cunha, R. S. (2007). What is the Effect of the Use of Baby Walker on Motor Development in Typically Developing Children? Journal of Motor Control, Supplement, (11) S117. 
Nonis, K. P. (1996). A mixed longitudinal study of the development of lower limb preference and hopping performance in girls. Unpublished Doctoral Thesis, The University of Western Australia, Perth.

Nonis, K. P. (2005). Kindergarten teachers' views about the importance of preschoolers' participation in sports in Singapore. Early Child Development and Care, $175(7 \& 8), 719-742$.

Nonis, K. P., Larkin, D., \& Parker, H. E. (2006). Perference in girls' lower limb Tasks. Journal of Physical Education \& Recreation (Hong Kong), 12(1), $39-47$.

Nonis, K. P., \& Parker, H. E. (2005). Lateral preference and performance asymmetry in girls' hopping skills. The Asian Journal of Exercise \& Sports Science, 1(2), 55-60.

Pollatou, E., Karadimou, K., \& Gerodimos, V. (2005). Gender differences in musical aptitude, rhythmic ability and motor performance in preschool children. Early Child Development and Care, 175(4), 361-369.

Siegel, A. C., \& Burton, R. V. (1999). Effects of baby walkers on motor and mental development in human infants. Journal of Developmental and Behavioral Pediatrics, 20(5), 355-361.

Sigmundsson, H., \& Rostoft, M. S. (2003). Motor Development: Exploring the motor competence of 4year-old Norwegian Children. Scandinavian Journal of Education Research, 47(4), 451-459.

Tan, N. C., Lim, L. H., \& Gu, K. (2003). Factors influencing caregiver's use of an infant walker. Asia Pacific Family Medicine, 2, 16-22.

Thein, M. M., Lee, J., \& Tay, V. (1997). Infant walker use, injuries, and motor development. Injury Prevention, 3, 63-66.

Thelen, E., \& Smith, L. B. (1994). A dynamic systems approach to the development of cognition and action. MA: The MIT Press.
Thomas, J. R. (2001). Children's motor behavior: Implications for teachers, coaches and parents. Unpublished Occasional Research Paper \#3, The Iowa Academy of Education, Iowa.

Ulrich, D. A. (2000). Test of Gross Motor Development $\left(2^{\text {nd }}\right.$ ed). TX: Pro-Ed Inc.

Wang, J. (2004). A study of gross motor skills of preschool children. Journal of Research in Childhood Education, 19(1), 32-43.

Whitall, J., \& Getchell, N. (1995). From walking to running: Applying a dynamical systems approach to the development of locomotor skills. Child Development, 66, 1541-1553.

Wong, A., \& Cheung, S. Y. (2006). Gross motor skills performance of Hong Kong Chinese children. Journal of Physical Education \& Recreation (Hong Kong), $12(2), 23-29$

Zachopoulou, E., \& Makri, A. (2005). A developmental perspective of divergent ability in early young children. Early Child Development and Care, 175(1), 85-95.

* The data reported here formed part of the first author's Masters in Early Childhood in the Early Childhood and Special Needs Education Academic Group, NTU/NIE.

\section{Correspondence:}

Karen P. Nonis

Early Childhood and Special Needs Education

Academic Group,

Nanyang Techological University/

National Institute of Education,

1 Nanyang Walk, Singapore 637616,

SINGAPORE.

Email: karen.nonis@nie.edu.sg 